\title{
Langmuir
}

\author{
pubs.acs.org/Langmuir
}

(C) 2010 American Chemical Society

\section{Spontaneous Formation of Hierarchically Structured Curly Films of Nickel Carbonate Hydrate through Drying}

\author{
Xiao-Hui Guo, ${ }^{\dagger,}$ Shu-Hong Yu, ${ }^{\dagger}, \dagger$ Yang Lu, ${ }^{\dagger}$ Guang-Bi Yuan,${ }^{\dagger}$ Miloš Sedlák, ${ }^{\S}$ and Helmut Cölfen ${ }^{\|}$ \\ Division of Nanomaterials \& Chemistry, Hefei National Laboratory for Physical Sciences at Microscale, \\ Department of Chemistry, University of Science and Technology of China, Hefei 230026, P. R. China, ${ }^{\ddagger}$ Key Lab \\ of Synthetic and Natural Functional Molecule Chemistry of Ministry of Education, and the School of Chemical \& \\ Materials Science, Northwest University, Xi'an 710069, P. R. China, ${ }^{\S}$ Institute of Organic Chemistry and \\ Technology, Faculty of Chemical Technology, University of Pardubice, nám. Čs. legii 565, 53210 Pardubice, \\ Czech Republic, and I" Department of Colloid Chemistry, Max Planck Institute of Colloids and Interfaces, MPI \\ Research Campus Golm, D-14424 Potsdam, Germany
}

Received January 17, 2010. Revised Manuscript Received February 25, 2010

\begin{abstract}
Novel curly nickel carbonate hydrate film superstructures can be prepared for the first time via a facile drying process of the films formed on air/solution interface in the presence of double hydrophilic copolymer or polyelectrolyte additives. As-prepared curly film patches with average edge sizes of several hundred micrometers display adjustable curly features along different orientation. The coiling up degree of the film edges is strongly dependent on the polymer concentration in bulk solution. Most of these curly structures have a relatively smooth outer surface; however, the microstructures of the outer surface of curly films formed show porous network-like features. In addition, using different kinds of nickel salts can produce distinct curly film samples. A possible formation mechanism of the curly film structure has been proposed. The multiple interaction modes between nickel salt precursors and polymer can favor the self-organization of the film formed at the air/solution interface. This approach is expected to be extended for producing a variety of curly hierarchical structures.
\end{abstract}

\section{Introduction}

Systems far from equilibrium can exhibit complex transitory structures, even when equilibrium fluctuations are mundane. ${ }^{1}$ Recently, an example of this phenomenon has been demonstrated for the formation of thin films of passivated nanocrystals during the irreversible evaporation of the solvent or drying process. ${ }^{2-4}$

In contrast, the phenomenon of solid film formation at the air/ solution interface is well-known to anyone who has left a halffinished cup of coffee or tea standing around for a few hours. Such films at solution interfaces form from complex mixtures of polymeric species and smaller molecules, but under more controlled conditions, these films may comprise highly ordered nanostructures or hierarchical superstructures. ${ }^{5}$ The spontaneous formation of such films may prove to be a currently unexploited method to make useful thin nanostructure membranes and films for a variety of applications in areas ranging from medical technologies to solar cell manufacture.

The spontaneous formation of thin films at the air/substrate or solution interface has been observed in both inorganic and organic systems but almost always in conjunction with surfactants

*Correspondence should be addressed to S. H. Yu, Fax: +86 5513603040 , E-mail: shyu@ustc.edu.cn.

(1) (a) Bray, A. J. Adv. Phys. 1994, 43, 357. (b) Tanaka, H. J. Phys. Condens. Matter 2000, 12, R207.

(2) (a) Ge, G.; Brus, L. E. J. Phys. Chem. B 2000, 104, 9573. (b) Tang, J.; Ge, G.; Brus, L. E. J. Phys. Chem. B 2002, 106, 5653.

(3) (a) Puntes, V. F.; Krishnan, K. M. Science 2001, 291, 2115. (b) Whitesides, G. M.; Grzybowski, B. Science 2002, 295, 2418. (c) Fried, T.; Shemer, G. Adv. Mater. 2001, 13, 1158

(4) (a) Rabani, E.; Reichman, D. R.; Geissler, P. L.; Brus, L. E. Nature 2003, 426, 271. (b) Bigioni, T. P.; Lin, X. M.; Nguyen, T. T.; Corwin, E. I.; Witten, T. A.; Jaeger, H. M. Nat. Mater. 2006, 5, 265. (c) Huang, J. X.; Kim, F.; Tao, A.; Connor, S.; Yang, P. D. Nat. Mater. 2005, 4, 896.

(5) (a) Huang, X.; Liu, M. H. Langmuir 2006, 22, 4110. (b) Edler, K. J. Soft Mater. 2006, 2, 284. or other additives. For example, the spontaneous formation of surfactant-templated thin films at the air/solution interface was reported independently by two research groups in $1996 .{ }^{6}$ Film formation at the solution surface occurs only under a limited range of conditions, some of which lead to precipitation. However, ordered solid nanostructures may also form solely as films at the solution surface, under conditions where only soluble composites are found in the subphase solution. Ordered and better oriented solid silica films can also be formed on solid substrates ${ }^{7}$ such as silicon and mica. In addition, solid films of silicongermanium can be spontaneously rolled up into nanotubes located on the silicon substrate by adopted etching technique. ${ }^{8}$ It has been demonstrated that multilayered nanostructure films can be formed at the solid/solution interface by using a layer-bylayer technique. ${ }^{9}$ However, unlike air-solution interface films, these ordered films do not form spontaneously from a mixture of both polyelectrolytes, since strong interactions between the oppositely charged pairs cause precipitation in the bulk solution if the two molecules are mixed, rather than spontaneous formation of ordered structures at the solution interface.

In general, surfactant-templated inorganic thin films formed at air/solution interface contain extremely well ordered mesostructures, usually aligned with respect to the solution surface. By tuning the surfactant additives, cubic ${ }^{10}$ and $3 \mathrm{D}$ connected micellar

(6) (a) Yang, H.; Coombs, N.; Sokolov, I.; Ozin, G. A. Nature 1996, 381, 589592. (b) Aksay, I. A.; Trau, M.; Manne, Honma, S. I.; Yao, N.; Zhou, L.; Fenter, P.; Eisenberger., P. M.; Gruner, S. M. Science 1996, 273, 892.

(7) Yang, H.; Kuperman, A.; Coombs, N.; Afara, S. M.; Ozin, G. A. Nature 1996, 379, 703.

(8) Schmidt, O.; Eberl, G. K. Nature 2001, 410, 168

(9) (a) Yang, B.; Edler, K. J. Chem. Mater. 2009, 21, 1221. (b) Ropers, M. H.; Norales, B.; Boue, F.; Axelos, M. A. V. Langmuir 2008, 24, 12849.

(10) Ruggles, J. L.; Holt, S. A.; Reynolds, P. A.; Brown, A. S.; Creagh, D. C.; White, J. W. Phys. Chem. Chem. Phys. 1999, 1, 323. 
hexagonal mesostructures ${ }^{11}$ can be produced. Most structures found in thin mesoporous films prepared by evaporation methods can also be produced by growth at the air/solution interface through appropriately selecting the type and properties of polymer additives. ${ }^{5 b}$ Apart from that, Scheinost et al. have reported the formation of layered single- and double-metal hydroxide precipitates at the mineral/water interface. ${ }^{12}$ In addition, the spontaneous precipitation of self-organized two-dimensional colloidal calcium carbonate crystals at air/water interface in an inorganic ion solution is possible. ${ }^{13}$

Interfacial phenomena have attracted increasing attention because of their potential applications and specific actions, including the interaction between particles and substrate in the past decades. ${ }^{14}$ Particularly, the drying process at an interface occurring on a specified substrate is especially interesting because it allows for a higher degree of convection-induced motion during evaporation of the solvent. ${ }^{2}$ To the best of our knowledge, crystallization at air/solution interface has been rarely studied in a closed system like the one used for gas diffusion reactions until now. ${ }^{15}$ In such a system, the reactants meet first at the airsolution interface which makes them very suitable for the formation of thin films at specific substrate interfaces.

In this study, we demonstrate the facile synthesis of curly nickel carbonate hydrate films with well-defined and curly multilayered superstructures at the air/glass interface through combination of a facile drying process with a biomimetic strategy by using a double hydrophilic block copolymer (DHBC) ${ }^{16}$ so-called methoxypoly(ethylene glycol)- $b$-poly(ethyleneimine)- $N$-poly(2,6-dideoxyD-arabino-hexanoic acid hydrazide (PEG-PEI- $\left(\mathrm{CH}_{2}-(\mathrm{CH}-\mathrm{OH})_{3}-\right.$ $\left.\mathrm{CH}_{2} \mathrm{CONHNH}_{2}\right)_{3}$ ) as additive (Scheme 1). We can prepare different hierarchically curly film samples via adjusting the polymer concentration in solution, additionally, only altering the kinds of nickel salt precursor can also obtain curly film structure. A possible formation mechanism of the curly film structure will be discussed.

\section{Experimental Section}

All chemicals are of analytical grade. Ammonium carbonate and nickel salts were purchased from Shanghai Chemical Reagent Company and used as received without further purification.

2.1. Synthesis of PEG-PEI- $\left(\mathrm{CH}_{2}-(\mathrm{CH}-\mathrm{OH})_{3}-\mathrm{CH}_{2} \mathrm{CO}-\right.$ $\left.\mathrm{NHNH}_{2}\right)_{3}$ (Methoxypoly(ethylene glycol)- $b$-poly(ethyleneimine)- $N$-poly (2,6-dideoxy-D-arabino-hexanoic acid hydrazide)). A solution of 6-bromo-2,6-dideoxy-D-arabino-hexanoic acid hydrazide $(5 \mathrm{~g}, 0.02 \mathrm{~mol})$ in dichloromethane $(30 \mathrm{~mL})$ was added to a solution of methoxypoly(ethylene glycol)- $b$-poly(ethyleneimine) $\left(10 \mathrm{~g}, M=5700 \mathrm{~g} \cdot \mathrm{mol}^{-1}\right)$ and triethylamine $(20 \mathrm{~g}, 0.2 \mathrm{~mol})$ in dichloromethane $(50 \mathrm{~mL})$. The synthesis of this copolymer is described elsewhere. ${ }^{17}$ After refluxing overnight, the mixture was evaporated to dryness and mixed with water $(50 \mathrm{~mL})$. The solution of the crude modified copolymer was further purified by exhaustive dialysis against distilled water using a Spectra Pore membrane with $\mathrm{MWCO}$ of $1000 \mathrm{~g} \cdot \mathrm{mol}^{-1}$. After final lyophilization,

(11) Tolbert, S. H.; Schaffer, T. E.; Feng, J.; Hansma, P. K.; Stucky, G. D. Chem. Mater. 1997, 9, 1962.

(12) Scheinost, A. C.: Sparks, D. L. J. Colloid Interface Sci. 2000, 223, 167.

(13) Wickman, H. H.; Korley, J. N. Nature 1998, 393, 445.

(14) For reviews, see: (a) Shen, Y. R.; Ostroverkhov, V. Chem. Rev. 2006, 106, 1140. (b) Benjamin, I. Chem. Rev. 2006, 106, 1212. (c) Jungwirth, P.; Tobias, D. J. Chem. Rev. 2006, 106, 1259. (d) Caro, A. L.; Nino, M. R. R.; Patino, J. M. R. Colloids Surf., A 2009, 332, 180 .

(15) (a) Weiner, S.; Albeck, S.; Addadi, L. Chem-Eur. J. 1996, 2, 278. (b) Yu, S. H.; Cölfen, H. J Mater. Chem 2004, 14,2124 (c) Guo, X. H. Yul, S. H. Cryst. Growth Des. 2007, 7, 354. (d) Chen, S. F.; Zhu, J. H.; Jiang, J.; Cai, G. B.; Yu, S. H. Adv. Mater. 2010, 22,540 .

(16) (a) Sedlak, M.; Antonietti, M.; Cölfen, H. Macromol. Chem. Phys. 1999, 2 , 247. (b) Sedlak, M.; Cölfen, H. Macromol. Chem. Phys. 2001, 202, 587.

(17) Bock, K.; Lundt, I.; Pedersen, C. Acta Chem. Scand. Ser. B 1984, $38,555$.
Scheme 1. Structural Formula of PEG-PEI- $\left(\mathrm{CH}_{2}-(\mathrm{CH}-\mathrm{OH})_{3}-\right.$ $\left.\mathrm{CH}_{2} \mathrm{CONHNH}_{2}\right)_{3}$ (Methoxypoly(ethylene glycol)- $b$-poly(ethyleneimine)- $N$-poly (2,6-dideoxy-D-arabino-hexanoic acid hydrazide) Denoted as Polymer A

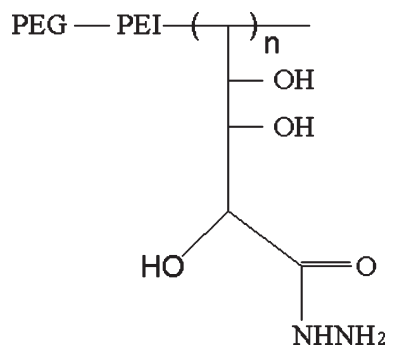

the product was obtained as a fine yellowish powder $(8.2 \mathrm{~g}, 73 \%)$. ${ }^{1} \mathrm{H} \mathrm{NMR}\left(400 \mathrm{MHz}, 25^{\circ} \mathrm{C}, \mathrm{CDCl}_{3}\right) \delta=2.43-2.64\left(\mathrm{~m}, 6 \mathrm{H} ; \mathrm{CH}_{2}\right.$ and $\left.\mathrm{m}, 64 \mathrm{H} ; \mathrm{CH}_{2} \mathrm{CH}_{2} \mathrm{~N}\right), 3.65\left(\mathrm{~m}, 456 \mathrm{H}, \mathrm{CH}_{2} \mathrm{CH}_{2} \mathrm{O}\right), 4.02(\mathrm{~m}$, $3 \mathrm{H} ; \mathrm{CH}-\mathrm{OH}), 4.67$ (m, 3H; $\mathrm{CH}-\mathrm{OH}), 4.73(\mathrm{~m}, 3 \mathrm{H} ; \mathrm{CH}-\mathrm{OH})$, $5.63(\mathrm{~m}, 3 \mathrm{H} ; \mathrm{CONH})$. Elemental analysis calcd $(\%)$ for $\mathrm{C} 52.46, \mathrm{H}$ 8.78, N 7.05; found C 52.72, H 8.85, N 6.85. $M_{\mathrm{w}}$ calcd: 6360 $\mathrm{g} \cdot \mathrm{mol}^{-1}$

2.2. Mineralization of Curly Hierarchical Structures of Nickel Carbonate Hydrate at the Air/Glass Interface. All glassware (glass bottle and small pieces of glass substrates) was cleaned and sonicated in ethanol for 5-10 min, then rinsed with nonionic water (NIW) $\left(18.2 \Omega \cdot \mathrm{cm}^{-1}\right)$ and further soaked with a $\mathrm{NIW} / \mathrm{HNO}_{3}(65 \%) / \mathrm{H}_{2} \mathrm{O}_{2}(1: 1: 1, \mathrm{v} / \mathrm{v} / \mathrm{v})$ solution, then rinsed with NIW, and finally dried with acetone. In a typical synthesis, the polymer additive was added to a selected nickel salt solution, for example, nickel chloride, nickel acetate, or nickel nitrate. The precipitation of nickel hydroxide compounds was carried out in glass bottles with volume $5-15 \mathrm{~mL}$, which were put in a closed desiccator at room temperature $\left(20 \pm 3{ }^{\circ} \mathrm{C}\right)$. Stock aqueous solution of nickel salt $(0.1 \mathrm{M})$ was freshly prepared in NIW. Five milligrams of polymer was added into $0.5 \mathrm{~mL}$ nickel salt solution $(0.1 \mathrm{M})$ containing $1 \mathrm{~g} \cdot \mathrm{L}^{-1}$ polymer for further crystallization experiment. The bottle was then covered with Parafilm, which was punched with three needle holes, and placed in a larger desiccator. Three small glass bottles $(10 \mathrm{~mL})$ of crushed ammonium carbonate were also covered with parafilm punched with three needle holes and placed at the bottom of the desiccator. After different periods of time, the parafilm was removed by using glass slice as film substrate. The slide slipped underneath the films so that the water side is now close to the slide, then the air-side of film still exists during the drying process. The whole drying dewetting process of films on the glass substrate will proceed with drying process occurring at air-solution interface, and the curly film samples can be obtained on glass slice and then collected for further characterization.

2.3. Characterization. The samples were characterized by X-ray diffraction pattern (XRD), recorded on a (Philips $\mathrm{X}^{\prime}$ Pert Pro Super) X-ray Powder diffractometer with Mo K $\alpha$ radiation $\left(\lambda_{\mathrm{Mo}}=0.70930 \AA\right)$. The infrared spectrum was obtained on a Fourier transform infrared spectrometer (FT-IR, Magna-IR750); the ingredients of the sample were detected by X-ray photoelectron spectroscopy (XPS), which was operated on an ESCALab MKII X-ray photoelectron spectrometer, using nonmonochromatized $\mathrm{Mg} \mathrm{K} \alpha \mathrm{X}$-ray as the excitation source.

The samples supported on small glass slices were examined by sputtering with gold for scanning electron microscopy (SEM) on a BYBY-1010A microscope or field emission scanning electron microscopy (FE-SEM) on a JSM-6700F microscope. Transmission electron microscopy (TEM) and high-resolution transmission electron microscopy (HRTEM), performed on a Hitachi (Tokyo, Japan) H-800 transmission electron microscope (TEM) at an accelerating voltage of $200 \mathrm{kV}$, and a JEOL-2010 highresolution transmission electron microscopy (HRTEM), also at $200 \mathrm{kV}$. The formation process of the curly film structure was 

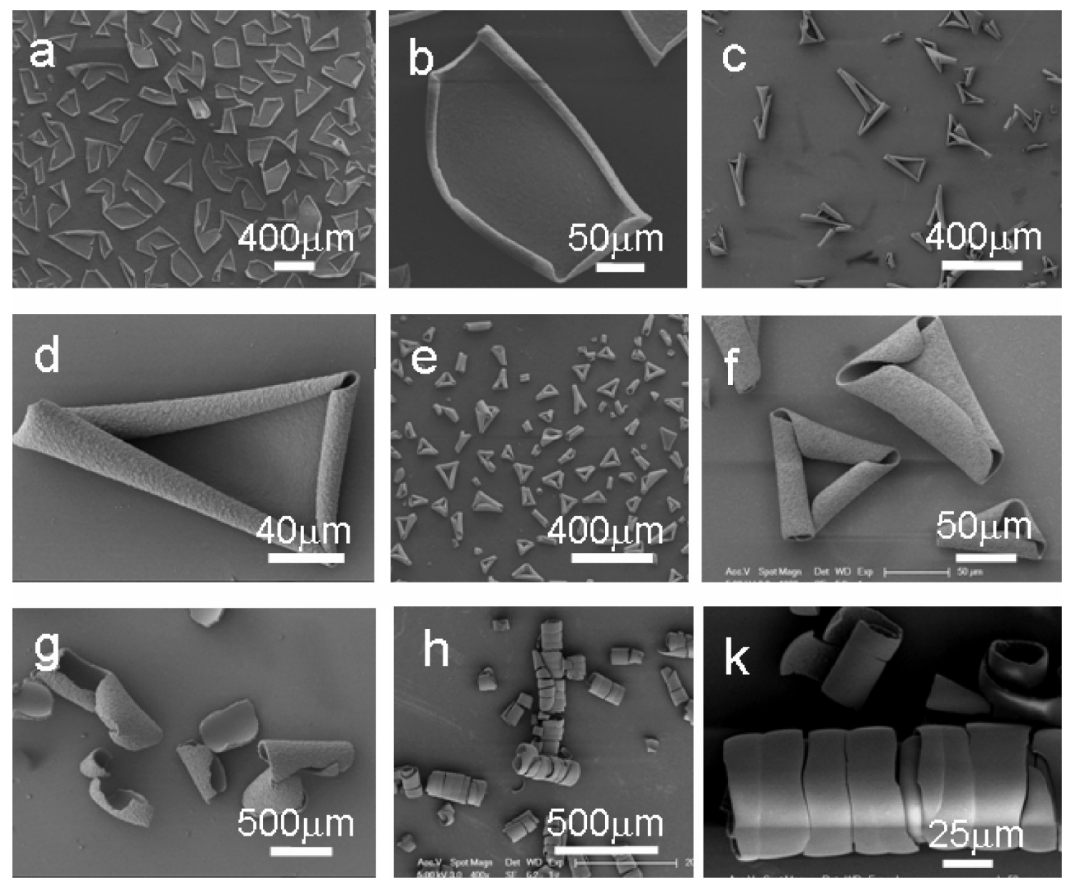

Figure 1. SEM images of the film-like samples of nickel carbonate hydrate formed at the air/glass slice after drying of the films formed at air/ solution interface in the presence of polymer A (PEG-PEI- $\left.\left(\mathrm{CH}_{2}-(\mathrm{CH}-\mathrm{OH})_{3}-\mathrm{CH}_{2} \mathrm{CONHNH}_{2}\right)_{3}\right)$ with different concentrations. (a) Curly film structures with multiple side edges, [polymer A] $=0.25 \mathrm{~g} \cdot \mathrm{L}^{-1}$. (b) Typical single curly structure with multiple sides in (a). (c) Teneral overview of curly film structures with three side edges, [polymer A] $=0.5 \mathrm{~g} \cdot \mathrm{L}^{-1}$. (d) Typical single curly structure with three side edges. (e) Curly film structure, [polymer A] $=1.0 \mathrm{~g} \cdot \mathrm{L}^{-1}$. (f) Magnified SEM image of (e). (g) Irregular curly patches structure. [polymer A] $=2.0 \mathrm{~g} \cdot \mathrm{L}^{-1}$. (h) Multiple-helical curly tubular structure formed with [polymer A] $=4.0 \mathrm{~g} \cdot \mathrm{L}^{-1}$. (k) Partial magnification of $(\mathrm{h})$ image. $\left[\mathrm{NiCl}{ }_{2}\right]=10 \mathrm{mM}$. The crystallization reaction proceeded for 2 days at ambient temperature.

screened and recorded on a NJF-1 type optical microscope. Thermogravimetric (TGA) analysis was carried out on a Diamond TG/DTA thermal analyzer (Perkin-Elmer Corporation) with a heat rate of $10{ }^{\circ} \mathrm{C} / \mathrm{min}$ at nitrogen atmosphere. The magnetic measurements on powdered samples enclosed in a medical cap were carried out at $4 \mathrm{~K}$ using a commercial superconducting quantum interference device (SQUID; MPMS-XL, Quantum Design, USA).

\section{Results and Discussion}

The mineralization reaction was performed using a previous gas diffusion process. ${ }^{15} \mathrm{~A}$ series of samples prepared in aqueous solution with different polymer concentrations at the air/glass interface after drying are curly thin films as shown in Figure 1. The curly film patches with sizes of several hundred micrometers display different features which are strongly dependent on the polymer concentration in bulk solution. It can be seen that the coiling up of the film edges directly correlates with the polymer concentration. While the edges just start to coil at a polymer concentration of $0.25 \mathrm{~g} \cdot \mathrm{L}^{-1}$ (Figure 1a), three side edges are formed at $0.5 \mathrm{~g} \cdot \mathrm{L}^{-1}$ and $1.0 \mathrm{~g} \cdot \mathrm{L}^{-1}$ (Figure $1 \mathrm{c}-\mathrm{e}$ ) with increasing coiling at higher polymer concentration. At a polymer concentration of $2.0 \mathrm{~g} \cdot \mathrm{L}^{-1}$, some curly fragments similar to tube-like structure formed (Figure 1g), while a hierarchically helical curly structure formed (Figure 1h) when the initial polymer concentration increased to $4.0 \mathrm{~g} \cdot \mathrm{L}^{-1}$. The curly structures have a relatively smooth outer surface (Figure 1i) and the microstructure of the inner surface of the tubular structure is similar to that shown in Figure 1d. Notably, apart from that, four further kinds of microstructures of the outer surface of curly films formed in the presence of polymer A with different concentration. All show porous cross-linking network-like features (Figure 2), which are opposite that formed in the case of polymer concentration of
$4.0 \mathrm{~g} \cdot \mathrm{L}^{-1}$. Clearly, the porous film surface becomes more compact with the polymer concentration increasing. In contrast to the curly films, the as-prepared samples in bulk solution and in the case of $1.0 \mathrm{~g} \cdot \mathrm{L}^{-1}$ only consist of irregular and bulk aggregates (see Supporting Information Figure S1). These aggregates consist of smaller nanoparticles with a size of ca. $50 \mathrm{~nm}$, which form network-like aggregated structures (see Supporting Information Figure S1b, c).

The XRD patterns confirm that the sample obtained in the presence of the polymer with different concentration can be indexed as the same phase of nickel carbonate hydrate monoclinic phase (JCPDS Card No. 24-0523) (Figure 4a). After thermal decomposition of the sample at $300{ }^{\circ} \mathrm{C}$ for $70 \mathrm{~min}$, which is obtained in the presence of polymer A, pure nickel oxide was obtained (Figure 4c). Both XPS spectra shown in Figure 3 and the energy disperses spectroscopy (EDS) spectrum (see Supporting Information Figure S2) also further confirmed the presence of Ni, $\mathrm{C}$, and $\mathrm{O}$ elements in the sample.

On the other hand, FT-IR spectra in Figure 5 showed that the as-prepared sample either in the absence or in the presence of polymer additive contains carboxyl groups, which further confirms the presence of carbonate groups in the curly films. Additionally, the sample formed in the presence of polymer A contains the amine groups and $\mathrm{C}=\mathrm{O}$ bonds as well as $\mathrm{CH}$ and $\mathrm{CH}_{2}$ bonds characteristic for the applied polymer (Figure 5a,b). The sample formed in the absence of the polymer can also be indexed as nickel carbonate hydrate (Figure 4b). The diffraction peaks become partially broadened and slightly shift toward higher diffraction angle, indicating this reference sample is made of crystalline nanoparticles with smaller sizes compared to that in the presence of the polymer.

On the other hand, the transmission electron (TEM) image of the sample obtained in the presence of $1.0 \mathrm{~g} \cdot \mathrm{L}^{-1}$ polymer A shows 

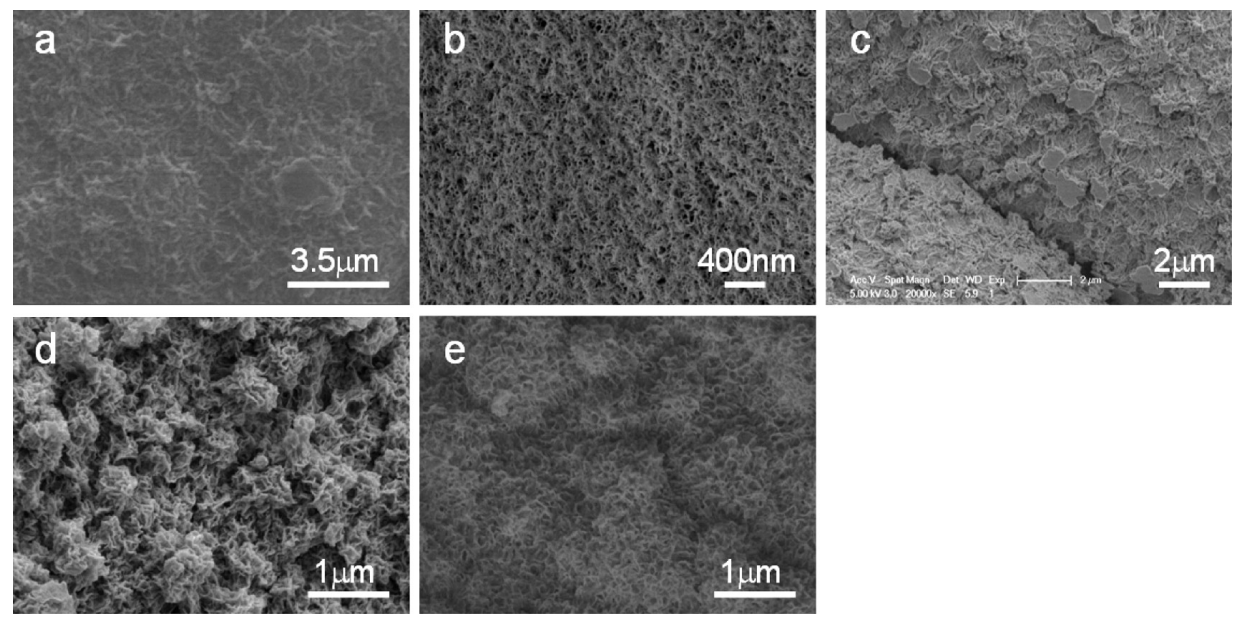

Figure 2. SEM images of the microstructures of nickel carbonate hydrate films formed at air/glass slice after drying of the films formed at air/ solution interface in the presence of polymer A $\left(\mathrm{PEG}-\mathrm{PEI}-\left(\mathrm{CH}_{2}-(\mathrm{CH}-\mathrm{OH})_{3}-\mathrm{CH}_{2} \mathrm{CONHNH}\right)_{3}\right)$ with different concentrations $(\mathrm{g} \cdot \mathrm{L}-1)$ : $(\mathrm{a})$ 0.25 , (b) 0.5 , (c) 1.0 , (d) 2.0 , and (e) 4.0 . $\left[\mathrm{NiCl}_{2}\right]=10 \mathrm{mM}$. The crystallization reaction proceeded for 2 days at ambient temperature.
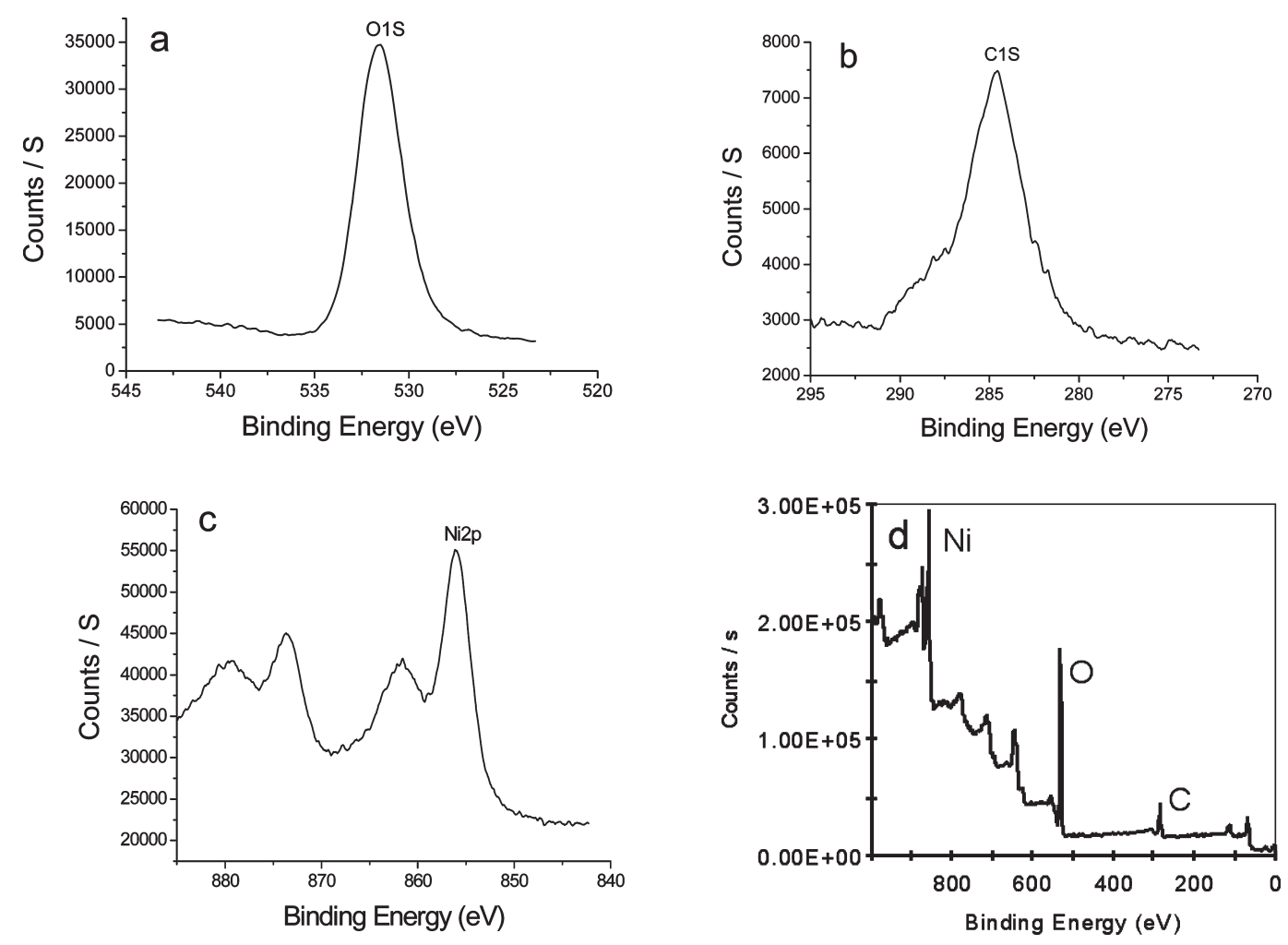

Figure 3. XPS spectrum of nickel carbonate hydrate curly films formed at the air/glass slice after drying of the films formed at air/solution interface in the presence of polymer A (PEG-PEI- $\left.\left(\mathrm{CH}_{2}-(\mathrm{CH}-\mathrm{OH})_{3}-\mathrm{CH}_{2} \mathrm{CONHNH}_{2}\right)_{3}\right)$ of $1.0 \mathrm{~g} \cdot \mathrm{L}^{-1}$. $\left[\mathrm{NiCl}_{2}\right]=10 \mathrm{mM}$. The crystallization reaction proceeded for 2 days at ambient temperature.

that the curly film-like sample is actually a network-like aggregate composed of flakes with smaller sizes (see Supporting Information Figure S3a), which is consistent with that observed by SEM. Selected area electron diffraction (SAED) pattern confirmed that the sample is polycrystalline (see Supporting Information Figure $\mathrm{S} 3 \mathrm{~b}$ ). Similar results were obtained in the case of a polymer a concentration of $2.0 \mathrm{~g} \cdot \mathrm{L}^{-1}$ (see Supporting Information Figure S3c,d). High-resolution TEM (HRTEM) image shows a lattice spacing of $2.55 \AA$, corresponding to the value for (206) planes of nickel carbonate hydrate (Figure 6). However, the single crystalline regions are very small and in the range of only a few nanometers, which is consistent with the size of $4 \mathrm{~nm}$ evaluated by the Scherrer equation from the wide-angle X-ray diffraction pattern (WAXS).

Thermogravimetric analysis (TGA) showed that the sample obtained in bulk solution contained less polymer included in the structures than that obtained at the air/solution interface (Figure 7). In addition, increasing the polymer concentration will also increase the amount of the polymer included in the film structures. It is well-known that nickel carbonate hydrate always undergoes multistep mass loss, and it has a larger mass loss (about $25 \mathrm{wt} \%$ ) in the region from 200 to $500^{\circ} \mathrm{C}$. The thermogravimetric curves of the four nickel carbonate hydrate samples at the temperatures ranging from 30 to $500{ }^{\circ} \mathrm{C}$ show two steps at ca. $100{ }^{\circ} \mathrm{C}$ and ca. 


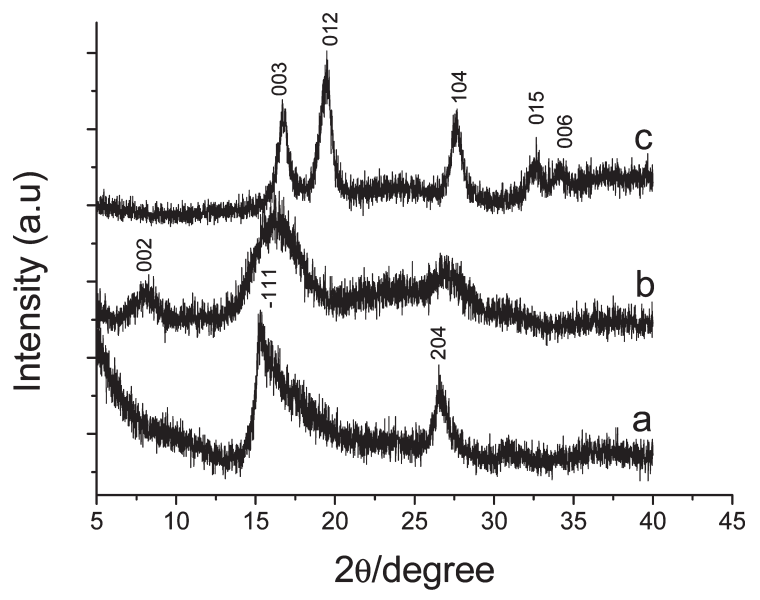

Figure 4. XRD patterns of the samples produced under different experimental conditions. (a) Sample obtained at the air/glass slice after drying of the films formed at air/solution interface in the presence of polymer A (PEG-PEI- $\left(\mathrm{CH}_{2}-(\mathrm{CH}-\mathrm{OH})_{3}-\mathrm{CH}_{2} \mathrm{CON}-\right.$ $\left.\left.\mathrm{HNH}_{2}\right)_{3}\right)\left(\left[\right.\right.$ polymer A] $\left.=1.0 \mathrm{~g} \cdot \mathrm{L}^{-1}\right)$. (b) Sample was collected at bottle bottom in the absence of polymer A. (c) After thermal decomposition at $300{ }^{\circ} \mathrm{C}$ of the sample in (a) for $70 \mathrm{~min}$.

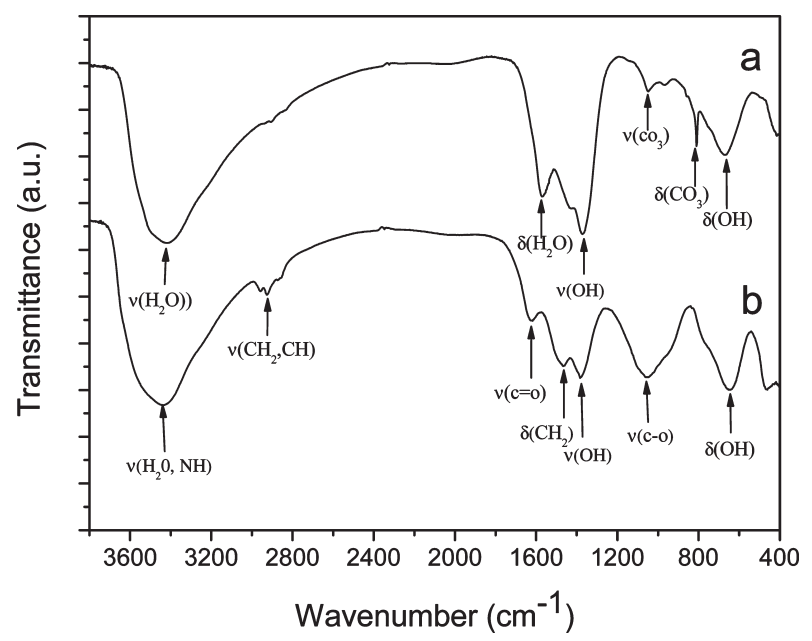

Figure 5. FT-IR images of the samples formed under different experimental conditions. (a) Without polymer additives, and (b) in the presence of polymer $\mathrm{A}\left(\mathrm{PEG}-\mathrm{PEI}-\left(\mathrm{CH}_{2}-(\mathrm{CH}-\mathrm{OH})_{3}-\mathrm{CH}_{2} \mathrm{CON}-\right.\right.$ $\left.\left.\mathrm{HNH}_{2}\right)_{3}\right)$. [polymer A] $=1.0 \mathrm{~g} . \mathrm{L}^{-1}$, and $\left[\mathrm{NiCl}_{2}\right]=10 \mathrm{mM}$. The crystallization reaction proceeded for 2 days at ambient temperature.

$250{ }^{\circ} \mathrm{C}$ with different net weight loss. The samples obtained at the air/solution interface in the presence of $1.0 \mathrm{~g} \cdot \mathrm{L}^{-1}$ and $4.0 \mathrm{~g} \cdot \mathrm{L}^{-1}$ show weight loss of 28.64 wt $\%$ and 37.59 wt $\%$, respectively (Figure 7b,d), the weight losses of $10 \mathrm{wt} \%$ and $16 \mathrm{wt} \%$ in the temperatures ranging from 20 to $250{ }^{\circ} \mathrm{C}$ are due to the loss of water and the incorporated polymer. With increasing of the polymer concentration, the content of polymer in the structures increased. The weight loss at the temperatures ranging from 250 to $500{ }^{\circ} \mathrm{C}$ is due to the conversion from nickel carbonate hydrate to nickel oxide.

According to the above results, the formation process of curly films is dependent on the polymer concentration, which is similar to that reported previously for the formation of surfactanttemplated mesoporous films grown at the air/water interface. ${ }^{18}$ When the polymer concentration increases, the included polymer

(18) Brennan, T.; Hughes, A. V.; Roser, S. J.; Mann, S.; Edler, K. J. Langmuir 2002, 18,9838 . content in the structures increases, and thus the coiling degree of film is also increasing. This is evidence for polymer interaction with the mineral. Such interaction is possible by complexing of nickel ions through nitrogen in amine or amide groups or carbonyl oxygen but also via hydrogen bonding between the polymer hydroxyl, amide, and carbonyl groups with the hydroxyl groups of the nickel carbonate hydrate. These multiple interaction modes can favor the self-organization of the film formed at the air/solution interface. ${ }^{19}$

The samples obtained at the air/glass interface and the use of different nickel salts as the nickel source show similar structures to those formed using nickel chloride as nickel source. When nickel nitrate was used as nickel resource, an irregularly shaped curly film structure formed, also exhibiting the network-like surface microstructure (Figure 8a,b), which is similar to the film structure formed in the case of $0.25 \mathrm{~g} \cdot \mathrm{L}^{-1}$ polymer. However, in the case of nickel acetate, completely cracked pieces of slab-like films formed (Figure 8c,d); the thickness of the films was measured to be $\sim 4.5 \mu \mathrm{m}$. The outer surface of the film was obviously rough compared to other nickel salt systems (Figure 8e). In addition, the XRD patterns indicated that samples formed in the case of nickel nitrate and nickel acetate could also be indexed as pure nickel carbonate hydrate monoclinic phase (see Supporting Information Figure S4), even though the crystallinity was low. In the case of nickel acetate, the crystallinity was higher and the diffraction peak -202 was additionally found compared to the case using nickel nitrate as the nickel source. The results indicated that the formation of curly film is mainly associated with the nickel-polymer complex regardless of the variation of the anion. The different anionic group types including $\mathrm{Cl}^{-}, \mathrm{NO}_{3}{ }^{2-}$, and $\mathrm{CH}_{3} \mathrm{COO}^{-}$can only influence the $\mathrm{pH}$ value and partial hydrolysis of nickel salts in aqueous solution. The influence of the nickel source on the morphologies of the film formed at the air/glass interface may result from the size dimension of the anions used and the difference of spacing occupied in octahedral coordination mode. ${ }^{20}$

Interestingly, the irregular multiple edge curly film structures can also be formed in the presence of PEG-PEI- $\left(\mathrm{CH}_{2}-\mathrm{COOH}\right)_{n}$ (Polymer B: methoxypoly(ethylene glycol)- $b$-poly(ethyleneimine)- $N$-poly(ethanoic acid)) (Figure $9 \mathrm{a}$ and Supporting Information Figure S5). Also, other organic additives with some specific functional groups such as poly(sodium-4-styrenesulfonate) (PSS), polyvinylpyrrolidone (PVP), poly(acrylic acid) (PAA), sodium dodecyl sulfate (SDS), and Dextrin have been used instead of polymer A. The results show that the curly film superstructure can also be produced in the presence of these additives with different anionic functional groups (Figure 9c,d), like a sulfonate or phosphonate group. In contrast, the side edges of the film tend to be only slightly or partly curled from the side edges (Figure 9e,f) in the presence of PVP. Secondary crimp of sheets located on the thicker slab occurred (Figure 9f). However, the curling was less pronounced or almost did not occur in the case of dextrin and PAA, respectively (see Supporting Information Figure S6). Thus, a general synthesis approach to curly structures at the air/substrate interface can be realized via the assistance of the different additive types with specific functional groups or variation of the polymer concentrations.

The detailed summary on the formation of the curly structures at the air/glass interface after crystallization at air/solution interface in the presence of selected polymer additives is given in Table 1.

(19) Firouzi, A.; Kumar, D.; Bull, L. M.; Besier, T.; Sieger, P.; Huo, Q.; Walker, S. A.; Zasadzinski, J. A.; Glinka, C.; Nicol, J.; Margolese, D.; Stucky, G. D.; Chmelka, B. F. Science 1995, 267, 1138.

(20) Vilminot, S.; Plouet, M. R.; Andre, G.; Swierczynski, D.; Vigneron, F. B.; Kurmoo, M. Inorg. Chem. 2003, 42, 6859. 

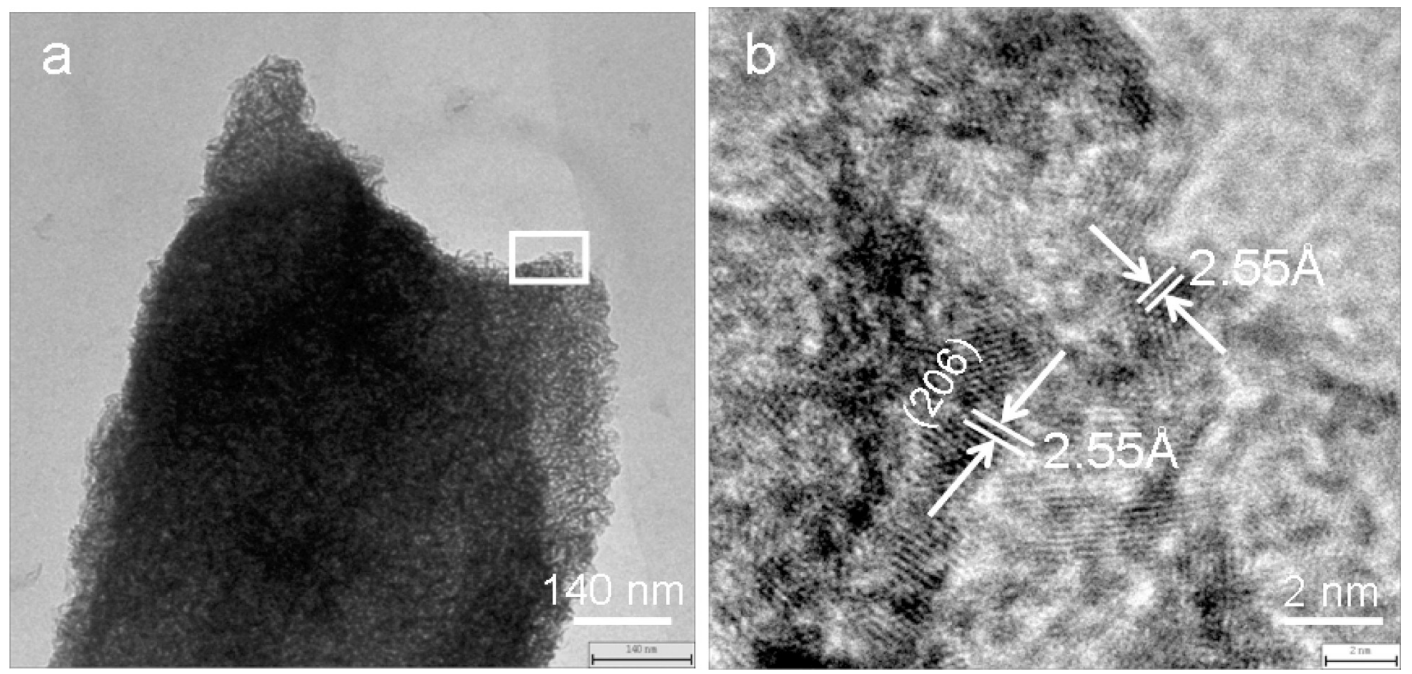

Figure 6. HRTEM images of a typical nickel carbonate hydrate slab-shaped film obtained through ultrasonic treatment of the curly film structure for $10 \mathrm{~min}$. (a) Typical slab-shaped structure, and (b) high-resolution TEM image taken in the selected area marked in (a). [polymer $\mathrm{A}]=1.0 \mathrm{~g} . \mathrm{L}^{-1}$, and $\left[\mathrm{NiCl}_{2}\right]=10 \mathrm{mM}$. The crystallization reaction proceeded for 2 days at ambient temperature.

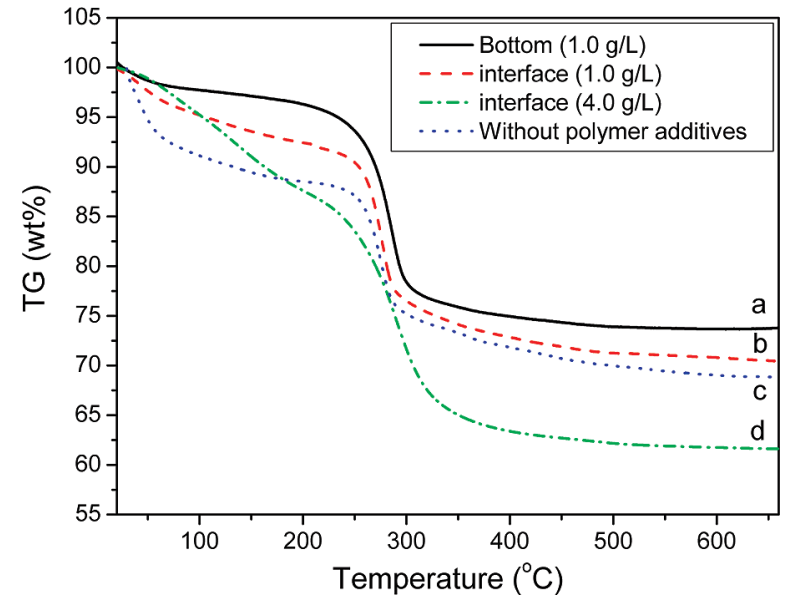

Figure 7. Thermogravimetric analysis (TGA) curves of the filmlike samples of nickel carbonate hydrate formed at the air/glass slice after drying of the films formed at air/solution interface in the presence of polymer A (PEG-PEI- $\left(\mathrm{CH}_{2}-(\mathrm{CH}-\mathrm{OH})_{3}-\mathrm{CH}_{2} \mathrm{CONH}-\right.$ $\left.\mathrm{NH}_{2}\right)_{3}$ ) with different concentrations. (a) In bulk solution, [polymer A] $=1.0 \mathrm{~g} \cdot \mathrm{L}^{-1}$. (b) At air/solution interface, [polymer $\mathrm{A}]=1.0 \mathrm{~g} \cdot \mathrm{L}^{-1}$. (c) In the absence of the polymer. (d) At air/solution interface, $[$ polymer $\mathrm{A}]=4.0 \mathrm{~g} \cdot \mathrm{L}^{-1} \cdot\left[\mathrm{NiCl}_{2}\right]=10 \mathrm{mM}$. The crystallization reaction proceeded for 2 days at ambient temperature.

The following correlations could be made. The curly films are only observed for polymeric binders. Low molar mass additives like SDS do not cross-link enough nanoparticles for formation of curly films. The polymers, with strong or multiple binding groups lead to coiling of the inorganic films. Weak binding via hydroxyl groups as in dextrin only works because of multiple binding sites. As the point of zero charge of $\mathrm{Ni}(\mathrm{OH})_{2}$ is $\mathrm{pH} 10.4 \pm 0.2$, the formed nanocrystals have an overall positive charge at the final $\mathrm{pH}$ of 9.5 in the gas diffusion reaction. This explains why the anionic polymers lead to curling, while other polymers only bind in a similar way if they have multiple binding sites or can complex $\mathrm{Ni}^{2+}$ via amine or carbonyl groups. Thus, binding of the polymer additive to multiple nanoparticles is a requisite for the formation of curly films.

More dramatic differences in the structures of the films formed in the case of different reaction environment. When all other experimental conditions were kept the same, but only the reaction kinetics is altered by carrying out the chemical reaction in a closed
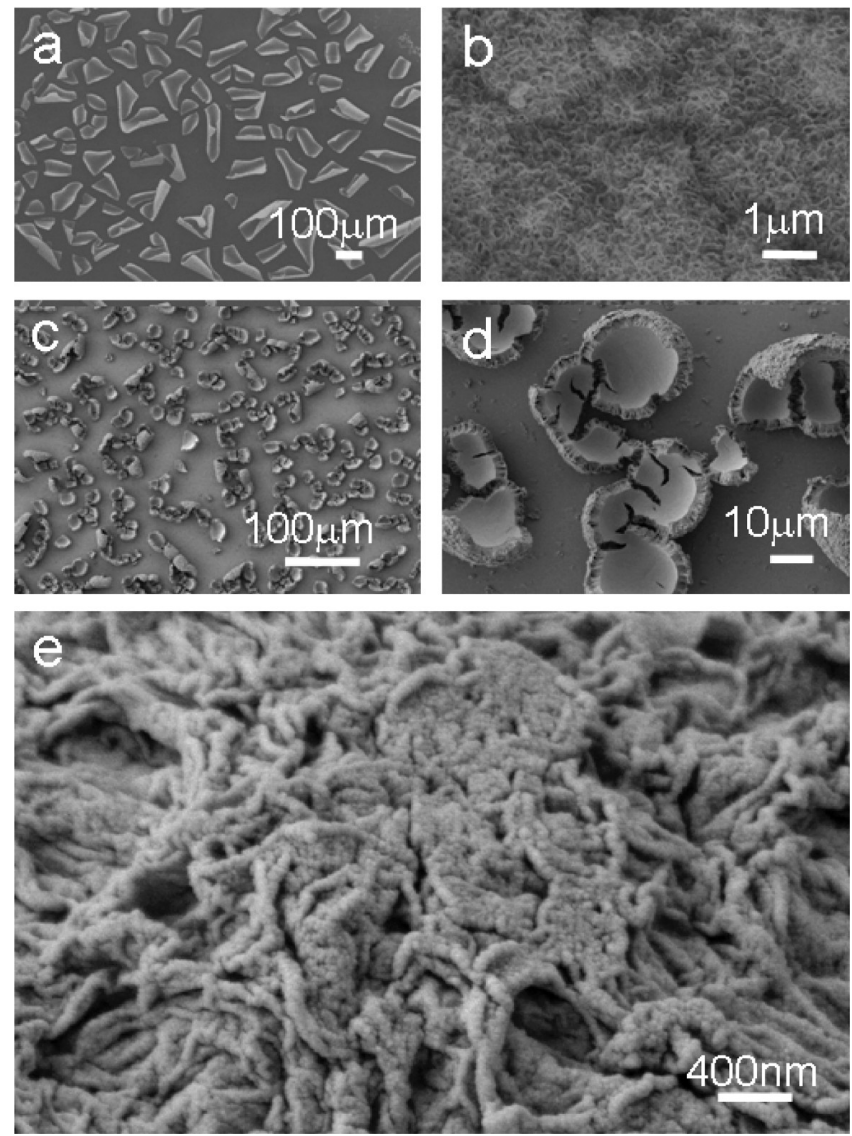

Figure 8. SEM images of the film-like samples of nickel carbonate hydrate formed at the air/glass slice after drying of the films formed at air/solution interface using different nickel salts as nickel resource in the presence of PEG-PEI- $\left(\mathrm{CH}_{2}-(\mathrm{CH}-\mathrm{OH})_{3}-\mathrm{CH}_{2} \mathrm{CONH}-\right.$ $\left.\mathrm{NH}_{2}\right)_{3}$. (a) Typical SEM images of curly structures formed using nickel nitrate as nickel resource. (b) Microstructure of the surface of curly slab in (a). (c) Typical SEM images of the curly structure formed by using nickel acetate as nickel source. (d) High-magnification SEM image of (c). (e) Surface microstructure of curly slab shown in (d). [polymer A] $=1.0 \mathrm{~g} \cdot \mathrm{L}^{-1}$. The concentrations of nickel acetate and nickel nitrate are $10 \mathrm{mM}$, respectively. The mineralization proceeded for 2 days at ambient temperature. 

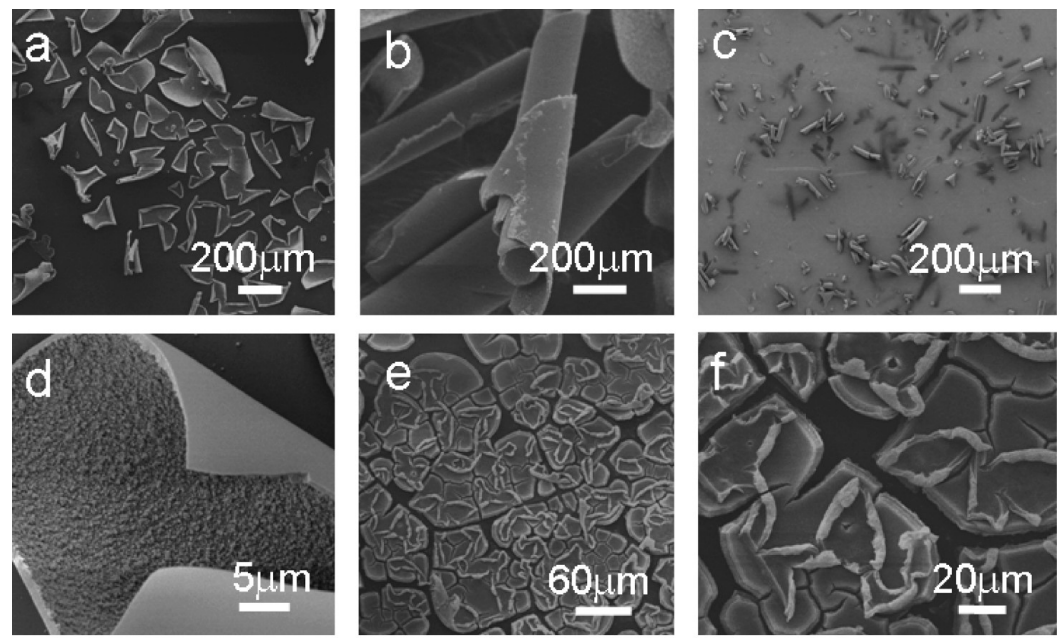

Figure 9. SEM images of the film-like samples of nickel carbonate hydrate formed at the air/glass slice after drying of the films formed at air/ solution interface in the presence of different polymer additives after mineralization for 2 days. (a) polymer $\mathrm{B}$ : $\mathrm{PEG}-\mathrm{PEI}-\left(\mathrm{CH}{ }_{2}-\mathrm{COOH}\right)_{n}$ (methoxypoly(ethylene glycol)- $b$-poly(ethyleneimine)- $N$-poly(ethanoic acid)). (b) PSS, (c,d) polymer C: PEG-PEI-(COC ${ }_{11} \mathrm{H}_{23}$ )$\left(\mathrm{CH}_{2} \mathrm{CH}_{2} \mathrm{PO}(\mathrm{OH})_{2}\right)_{n}$ (methoxypoly(ethylene glycol)- $b$-poly(ethyleneimine)- $N$-poly(dodecanoyl)- $N^{\prime}$-poly(ethyl phosphonic acid)). (e,f) PVP. The concentration of additives and nickel chloride were $1.0 \mathrm{~g} \cdot \mathrm{L}^{-1}$ and $10 \mathrm{mM}$, respectively.

Table 1. Summary of the Morphology of the Film-Like Sample of Nickel Carbonate Hydrate Formed at the Air/Glass Slice after Drying of the Films Formed at Air/Solution Interface in the Presence of Different Additives

\begin{tabular}{|c|c|c|c|}
\hline Additive types & Main functional groups & Morphologies of films & Chemical composition \\
\hline polymer A & $-\mathrm{OH},-\mathrm{C}=\mathrm{O},-\mathrm{NH}_{2}$ & hierarchical curly & nickel carbonate hydrate \\
\hline polymer B & $-\mathrm{OH},-\mathrm{COOH}$ & multiple-corner curly & nickel carbonate hydrate \\
\hline polymer C & $\begin{array}{r}\text { O } \\
-P\end{array}$ & partly and tube-like curly & nickel carbonate hydrate \\
\hline PVP & $\mathrm{C}=\mathrm{O}$, tert- $\mathrm{N}$ & $\begin{array}{l}\text { triangle-like(main) and } \\
\text { tube-like (partly) curly }\end{array}$ & nickel carbonate hydrate \\
\hline PSS & $-\mathrm{SO}_{3} \mathrm{H}$ & multiple-closed tube-like & nickel carbonate hydrate \\
\hline PAA & $-\mathrm{COOH}$ & partially curly and flat & nickel carbonate hydrate \\
\hline SDS & $-\mathrm{SO}_{4}$ & flat and chapped film patch & nickel carbonate hydrate \\
\hline Dextrin & -OH (multiple) & $\begin{array}{c}\text { triangle-like, tube-shape and } \\
\text { irregular curly }\end{array}$ & nickel carbonate hydrate \\
\hline
\end{tabular}

desiccator and slow $\mathrm{pH}$ rise through ammonia gas diffusion, and a completely open system with $\mathrm{pH}$ increasing by direct mixing, respectively, curled films were found for the present slow gas diffusion reaction. On the other hand, a nearly completely flat slab patch structure will form either at the air/solution interface or in bulk solution of the open system (see Supporting Information Figure S7).

The films grown at the air/substrate interface are a useful system for the investigation of the formation mechanism of polymer-directed inorganic materials. Nanoparticle-based composites form at the solution surface where the $\mathrm{pH}$ is most alkaline

(21) Neira-Carrillo, A.; Acevedo, D. F.; Miras, M. C.; Barbero, C. A.; Gebauer, D.; Cölfen, H.; Arias, J. L. Langmuir 2008, 24, 12496. due to the highest local ammonia concentration in analogy to a reactant gradient similar to gas diffusion methods like the Kitano method. $^{21}$ The primary nanoparticles including the polymer component will slightly enrich at the solution interface. In addition, even double hydrophilic block copolymers were found to be surface active and lower the water surface tension due to enrichment at the air-water interface. ${ }^{22}$ The mineral nanoparticles will aggregate by binding of the polymer, which will lead to patches of nanoparticle aggregates at the air-water interface.

The films can be ordered and directionally curly along specific orientations. It is proposed that the coiling of the films observed

(22) (a) Rudloff, J.; Cölfen, H. Langmuir 2004, 20, 991. (b) Gu, Z. Y.; Chen, Y. M.; Gracias, D. H. Langmuir 2004, 20, 11308. 


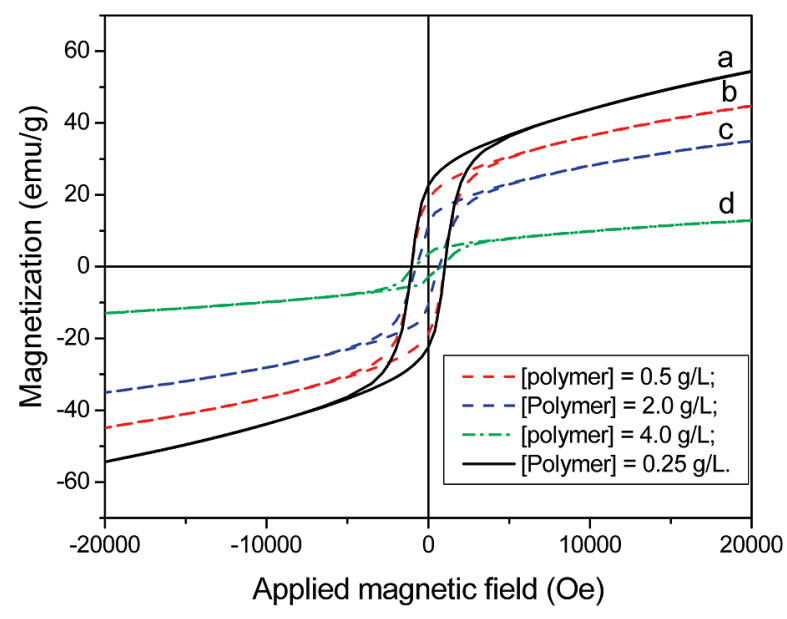

Figure 10. Isothermal magnetization curves at $300 \mathrm{~K}$ for nickel carbonate hydrate formed at the air/glass slice after drying of the films formed at air/solution interface in the presence of polymer A with different concentration after mineralization for 2 days. (a) $0.25 \mathrm{~g} \cdot \mathrm{L}^{-1}$, (b) $0.5 \mathrm{~g} \cdot \mathrm{L}^{-1}$, (c) $2.0 \mathrm{~g} \cdot \mathrm{L}^{-1}$, (d) $4.0 \mathrm{~g} \cdot \mathrm{L}^{-1}$. polymers are hydrophilic and therefore swollen, partial drying of the film facing air results in partial shrinking at that side and the

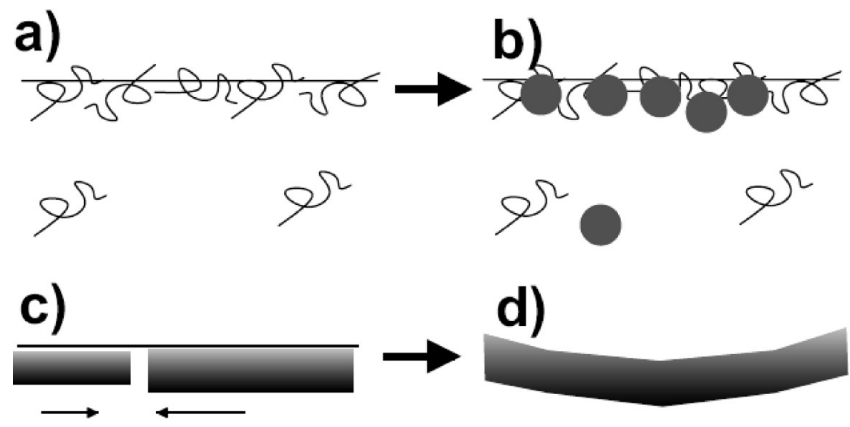

Figure 12. Schematic illustration of the curly film formation. (a) Polymer enrichment at the air-solution interface. (b) Nanoparticle formation at the air-solution interface and aggregation to aggregate patches at the surface. (c) Aggregation of several patches to films and (d) curling of patches after the initially formed film cracked after partial drying. Note that the gray to black gradient in (c) and (d) represents the decreasing polymer concentration in the film toward the solution phase.

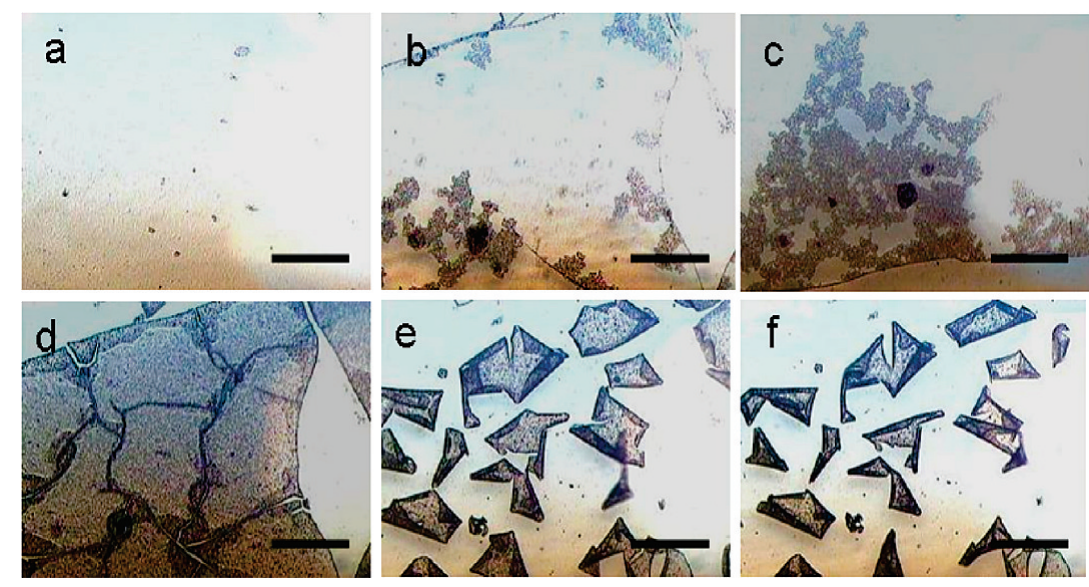

Figure 11. Optical microscopy $(\mathrm{OM})$ images of the curly process after the transferred the films from the air/solution interface on glass slide. The films were transferred on glass substrate after crystallization on air/solution interface for 2 days: (a) initial state of the sample after fresh transfer from the air/solution interface, (b) after $3 \mathrm{~s}$, (c) after $6 \mathrm{~s}$, (d) after $10 \mathrm{~s}$, (e) after $15 \mathrm{~s}$, and (f) after $30 \mathrm{~s}$. $\left[\mathrm{NiCl}_{2}\right]=10 \mathrm{mM}$. [polymer A] $=$ $1.0 \mathrm{~g} \mathrm{~L}^{-1}$. The scale bar is $400 \mu \mathrm{m}$.

here is associated to stress generated by uneven shrinking of the side of the film facing the glass slice and the one facing air during the drying process. In addition, the curly shape can be supported by the drying process of the film surface after it was taken from the solution surface. ${ }^{23}$ Then, capillary forces between nanoparticles can exert the dynamic self-assembly of nanoparticles of liquid films on the air/glass slice as the film dries on the glass slice. The case is also evidenced previously by self-assembly of $\mathrm{Au}$ nanoparticles on a silicon/silica substrate. ${ }^{4 \mathrm{c}}$ Thus, the property change of the polymer component, including concentration, additive type, functional group variation, and so on, can indeed mediate the structure change of the nickel carbonate hydrate film at the interface. The reason for this uneven shrinkage can be found in a polymer concentration gradient inside the film where the concentration at the interface to air is highest, since this was the region where the nanoparticle aggregation started in the polymer-enriched solution interface region. If the film grows toward the solution side via further attachment of nanoparticles, the copolymer concentration in this region is only that of the dissolved polymer in the bulk solution. Since all applied

(23) Tirumkudulu, M. S.; Russel, W. B. Langmuir 2005, 21, 4938. beginning of coiling. The phenomenon is very similar to the Marangoni effect produced in nanocrystal film self-assembly systems. $^{24}$

The higher the polymer concentration, the better the binding of the aggregated nanoparticles and the effect of coiling by deswelling will be, which is proportional to the local polymer content in the film. Moreover, we speculate that the specific magnetic interaction between nickel carbonate hydrate particles formed may assist the self-coiling of the film during drying, as seen by different magnetization curves as shown in Figure 10, while both the saturation magnetization and remanent magnetization decreased with increasing polymer concentration. The results suggested that the magnetic properties of the film composites could play a role for curling as they become weaker with increasing polymer concentration while the films become more curled, since then, the greater polymer component will participate in the coiling self-assembly process, which can lead to higher coiling degree. The strains generated among the films will become dominant and increase with polymer concentration.

(24) Maillard, M.; Motte, L.; Ngo, A. T.; Pileni, M. P. J. Phys. Chem. B 2000, 104,11871 
The whole formation processes of the curly film can be directly observed in a time-dependent manner under the optical microscope to reveal the evolution process (Figure 11). Mesostructured particles formed first at the air-solution interface leading to small aggregates at the surface caused by polymer binding (Figure 11a). Film formation is driven by the packing of these particle aggregate patches at the air/solution interface by diffusion and convection of the patches on the solution surface (Figure $11 \mathrm{~b}, \mathrm{c}) .^{4 \mathrm{a}, 15 \mathrm{c}, 22,25}$

Once the film gets larger and forms nanoparticle-based aggregates by attachment of further patches (Figure 11d), it starts to dry at the air interface, subsequently causing deswelling of the polymer and thus shrinking of the film at the surface facing air. Upon continued drying, these nanoparticles become much more coarsened along the drying front driven by the motion of the nanoparticles in terms of capillary forces, which results from the network-like structure of surface of the films as evidenced (Figure 2). Moreover, the film surface coarsening texture processes can be further evidenced form the coarse-grained lattice gas model proposed by Rabani and co-workers. ${ }^{26}$ Therefore, generated stresses and the effect of the friction interplayed between glass slice and drying film will lead to disruption of the film into patches and further coiling of film patches on the glass slice interface (Figure 11e,f), finally leading to the formation of curly films. The whole formation process can be schematically illustrated in Figure 12.

(25) Edler, K. J.; Goldar, A.; Hughes, A. V.; Roser, S. J.; Mann, S. Microporous Mesoporous Mater. 2001, 44-45, 661.

(26) Stzrum, C. G.; Hod, O.; Rabani, E. J. Phys. Chem. B 2005, 109, 6741.

\section{Conclusions}

In summary, we report a simple approach for the synthesis of curly hierarchical structures of nickel carbonate hydrate at the air/ glass slice after drying of the films formed at air/solution interface in the presence of a variety of organic additives such as double hydrophilic block copolymers or polyelectrolyte additives. The results demonstrated that the polymer concentration, additive types with specific functional groups, and thermodynamic state can result in the formation of various morphologies of the asprepared nickel carbonate hydrate film superstructures. Altering additive types or the nickel source can also modulate the degree of coiling in the film superstructures. The coiling of the films could be explained by a polymer concentration gradient toward the aqueous phase inside the patches consisting of aggregated polymer connected mineral nanoparticles. This approach is expected to be extended for producing a variety of curly hierarchical structures.

Acknowledgment. S.H.Y. acknowledges the funding support from the National Basic Research Program of China (2010CB934700), the Program of International S \& T Cooperation (S2010GR0314), and the National Natural Science Foundation of China (Nos. 50732006), and Dr. Rongjin Li in Institute of Chemistry, Chinese Academy of Sciences.

Supporting Information Available: SEM images, TEM images, electron diffraction patterns, EDS spectrum, and XRD patterns of the samples are available. This material is available free of charge via the Internet at http://pubs. acs.org. 